Volume 11 | Issue 4

November 2020

\title{
A Journey of Doing Research "In a Good Way": Partnership, Ceremony, and Reflections Contributing to the Care and Wellbeing of Indigenous Women Living with HIV in Canada
}

\author{
Doris Peltier \\ Canadian Aboriginal AIDS Network, Canada, dorpeltier@yahoo.ca
}

Carrie Martin

Mi'gmaq, Canadian Aboriginal AIDS Network, Canada, carriem@caan.ca

Renée Masching

Canadian Aboriginal AIDS Network, Canada, reneem@caan.ca

Mike Standup

Elder, Mohawk Nation, mikestandup@hotmail.com

Claudette Cardinal

Plains Cree, Faculty of Health Sciences, Simon Fraser University, Canada, claudette.cardinal@hotmail.com

Valerie Nicholson

Faculty of Health Sciences, Simon Fraser University, Canada, vjnicholson@live.ca

Mina Kazemi

Women's College Research Institute, Women’s College Hospital, Canada, mina.kazemi@wchospital.ca

Angela Kaida

Faculty of Health Sciences, Simon Fraser University, Canada, kangela@sfu.ca

Laura Warren

Women's College Research Institute, Women’s College Hospital, Canada, lawarren@gmail.com 
Denise Jaworsky

Northern Medical Program, University of Northern British Columbia, Canada, denisewj@gmail.com

\section{Laverne Gervais}

Ka Ni Kanichihk, Canada, lgervais@kanikanichihk.ca

\section{Alexandra de Pokomandy}

Department of FamilyMedicine, McGill University, Canada, alexandra.depokomandy@mcgill.ca

\section{Sharon Bruce}

Max Rady College of Medicine, Rady Faculty of Health Sciences, University of Manitoba, Canada, sharon.bruce@umanitoba.ca

\section{Saara Greene}

School of Social Work, McMaster University, Canada, greenes@mcmaster.ca

\section{Marissa Becker}

Centre for Global Public Health, Department of Community Health Sciences, University of Manitoba, Canada, marissa.becker@umanitoba.ca

\section{Jasmine Cotnam}

Canadian Aboriginal AIDS Network, Canada, jasminec@caan.ca

\section{Kecia Larkin}

Pikanii Nation and Kwa'kwa'ka'wakw Nation, kecialarkin@gmail.com

\section{Kerrigan Beaver}

Women’s College Research Institute, Women’s College Hospital, Canada, kcbeaver007@yahoo.ca

\section{Carrie Bourassa}

College of Medicine, University of Saskatchewan, Canada, carrie.bourassa@usask.ca

\section{Mona Loutfy}

Women’s College Research Institute, Women’s College Hospital, Canada, mona.loutfy@wchospital.ca

\section{Recommended Citation}

Peltier, D., Martin C, Masching, R., Standup, M., Cardinal, C., Nicholson, V., Kazemi, M., Kaida, A., Warren, L., Jaworsky, D., Gervais, L., de Pokomandy, A., Bruce, S., Greene, S., Becker, M., Cotnam, J., Larkin, K., Beaver, K., Bourassa, C., \& Loutfy M. (2020). A journey of doing research "in a good way": Partnership, ceremony, and reflections contributing to the care and wellbeing of Indigenous women living with HIV in Canada. The International Indigenous Policy Journal, 11(4). http://doi.org/10.18584/iipj.2020.11.4.8215 


\title{
A Journey of Doing Research "In a Good Way": Partnership, Ceremony, and Reflections Contributing to the Care and Wellbeing of Indigenous Women Living with HIV in Canada
}

\begin{abstract}
The relationship between the First Peoples of Canada and researchers is changing as processes of selfdetermination and reconciliation are increasingly implemented. We used storytelling and ceremony to describe a historic event, the Indigenous Women's Data Transfer Ceremony, where quantitative data of 318 Indigenous women living with HIV were transferred to Indigenous academic and community leaders. Relationship building, working together with a common vision, the Ceremony, and the subsequent activities were summarized as a journey of two boats. The Truth and Reconciliation Commission of Canada's Calls to Action and Indigenous ethical principles were central to the process. The article ends with team members' reflections and the importance of shifting power to Indigenous Peoples in regard to data collection, their stories, and the resulting policies.
\end{abstract}

\section{Keywords}

Indigenous women, HIV, CHIWOS, data transfer, ceremony, Indigenous ethics, allyship, Truth and Reconciliation Commission of Canada, self-determination

\section{Acknowledgements}

The Canadian HIV Women's Sexual and Reproductive Health Cohort Study (CHIWOS) research team would like to especially thank all of the women living with HIV who participated in the research and entrusted CHIWOS with their experiences of HIV treatment, care, and support. We also thank the entire national team of coinvestigators, collaborators, and peer research associates. We would like to acknowledge the three provincial community advisory boards, and the national CHIWOS Indigenous Advisory Board, CHIWOS African, Caribbean and Black Advisory Board, and our partnering organizations for supporting the study. We also acknowledge the BC Centre for Excellence in HIV for in kind data management and analytic support.

\section{Creative Commons License (C) $(1) \Theta \Theta$}

This work is licensed under a Creative Commons Attribution-Noncommercial-No Derivative Works 4.0 License. 
Peltier et al.: A Journey of Doing Research "In a Good Way"

\title{
A Journey of Doing Research "In a Good Way": Partnership, Ceremony, and Reflections Contributing to the Care and Wellbeing of Indigenous Women Living with HIV in Canada
}

\author{
Creator, I am known as Rasennakohe (my Mohawk name). Bear Clan, Mohawk being the way \\ of my people. \\ Creator, I am asking you in the business we are all working at, that we use a good mind, a one \\ mind. To arrive at peaceful conclusions, using one mind and a good mind.
}

Opening Prayer, Elder Mike Standup

All people need information to understand, help, or solve the issues they are facing individually, collectively, and within their contexts (Rainie et al., 2017). Sometimes information is generated through formal research activities, and such information is termed "data." However, historically, there lies a tension when Indigenous Peoples are involved in research and research data are generated. The tension stems from the harm done by colonizers to the First Peoples of many countries, including Canada, resulting in distrust of colonial institutions. Further, in many cases, research to "collect data" about Indigenous Peoples has extracted information, often out of context, and offered no benefit to the community. This process article presents how we, as Indigenous community leaders and researchers and allied researchers in the field of HIV, came together to manage this research tension by continuously trying our best to do research "in a good way." Doing research in "a good way" has been outlined by our partners at the Canadian Aboriginal AIDS Network (CAAN) and the Aboriginal HIV/AIDS Community-Based Research Collaborative Centre (AHA Centre) as: (a) research that is done respectfully; (b) that benefits the community; (c) acknowledges that the process is just as, or more important, than the products; and (d) research in which relationship building and relational accountability are at its heart. CAAN (2011) and AHA Centre (2018), along with others (see for example Ball \& Janyst, 2008; Flicker et al., 2015; Kovach, 2005; Wilson, 2008), emphasize that doing research "in a good way" uses Indigenous ways, ensuring that Indigenous Peoples reclaim the ownership of their data and stories. Drawson et al. (2017) explained that Indigenous methods must go beyond data collection to creating relationships, supporting autonomy, facilitating capacity building, and allowing for community healing.

Specifically, this process article shares and explores the journey that began with collaboration between Mona Loutfy—an allied researcher-and Doris Peltier—an Indigenous woman, advocate, and now researcher, living with HIV — and the stories of hundreds of women and people who since 2011 have been impacted by this partnership. This journey of Indigenous leaders and allied researchers doing research "in a good way" has been guided by and is viewed as a way to enact the national Truth and Reconciliation Commission of Canada's (TRC, 2015a) Calls to Action. Using the Indigenous research methodology of storytelling, this article describes the journey or process of relationship building, 
working together, a monumental ceremony (i.e., the Indigenous Women's Data Transfer Ceremony), reflection, and the continuation together on a path of reconciliation.

\section{Background and Context}

This journey that we will share with you takes place in Canada, from the Huron-Haudenosaunee [Iroquois] word "Kanata," which likely means "village" or "settlement" (Government of Canada, 2020). Prior to colonization, Indigenous Peoples across Turtle Island, the name of the land named North America today, lived in independent villages or Nations that were self-governed and held collectively. The land was viewed, and is still viewed, as sacred, to be preserved for future generations, and to be lived on according to the teachings from nature. Territories were shared by one Nation, made up of many families and subgroups; there were alliances between Nations and not all Nations lived in harmony with one another. The arrival of settlers radically shifted this context, and the resulting introduction of Canadian policies, often designed with the intent to destroy Indigenous self-governance and individual rights and freedoms by assimilating Indigenous Peoples into mainstream culture, disrupted precolonial structures.

This intentional attack was achieved, in part, by breaking families apart through the establishment of Residential Schools that were mandated to "kill the Indian in the child"; a cultural genocide ensued (TRC, 2015b). The horrendous conditions experienced in these schools for more than 150 years resulted in the death of many children, trauma from sexual and physical abuse, loss of language and culture, separation from family, and much more. In 2009, a multi-year process to capture the stories of Survivors and those impacted by the Residential Schools was launched as the TRC (2015a). The result was the 2015 release of a collection of reports and 94 Calls to Action meant to support the process of reconciliation in Canada (TRC, 2015a).

Colonialism in Canada has been an ongoing, heavily bureaucratic process reliant upon knowledge created about (rather than with and for) Indigenous Peoples for the purposes of land, economic, and social control. Indigenous Peoples' identities have not only been separated by the Nations they belonged to, but by the arbitrary, broad terms that the Canadian government bestowed on Indigenous Peoples: First Nations (for Nations south of the Arctic Circle), Inuit (a large Nation living in the Arctic region from Greenland and Eastern Canada to Alaska), and Métis (a distinct heritage of those of mixed First Nation and European settler descent, particularly linked with the fur trade).

Colonialism and assimilation of Indigenous Peoples through the removal of people from their land, Residential Schools, assault on Indigenous cultures, and segregating the health care system underlie the many social and health inequities that Indigenous Peoples experienced and still experience today. It was not until 1979 that the Government of Canada adopted the Indian Health Policy (1979), emphasizing the responsibility of both the federal and provincial governments to provide health services to First Nations and Inuit ${ }^{1}$ and that communities could control any or all aspects of the administration of their

\footnotetext{
${ }^{1}$ Under Canada's Constitution, health care services fall under the jurisdiction of provincial or territorial governments; however, First Nations with Indian Status and Inuit fall under federal jurisdiction in all areas including health care (Government of Canada, n.d.).
} 
own community health programs at their discretion and with the support of the Department of National Health and Welfare.

The TRC Calls to Action highlight the need to reduce health inequities experienced by Indigenous Peoples and urge the establishment of measurable goals to identify and close gaps in health outcomes. The TRC (2015a) reports call upon research and data collection to uphold high ethical standards, particularly given the historical and ongoing misuse of information about Indigenous cultures and communities.

These ethical standards began to be articulated in Canada in 1998, first by First Nation communities as the OCAP $^{\circledast}$ principles (First Nations Information Governance Centre [FNIGC], 2015) and then with equivalent Métis (National Aboriginal Health Organization [NAHO], n.d.) and Inuit principles (Inuit Tapiriit Kanatami [ITK], 2018), giving voice to a set of standards designating how Indigenous data must be gathered, used, and disseminated. The $\mathrm{OCAP}^{\circledR}$ acronym, which stands for Ownership, Control, Access and Possession, demands that First Nations communities have protection and control of their information and how it is used.

The Government of Canada followed with guidelines for research involving First Nations, Inuit, and Métis Peoples of Canada. These guidelines were incorporated into Chapter Nine of the national guide for all research involving human subjects, Tri-Council Policy Statement (TCPS2): Ethical Conduct of Research Involving Humans (Canadian Institutes of Health Research [CIHR] et al., 2018). This chapter is designed to serve as a framework for the ethical conduct of research involving Indigenous Peoples in Canada, ensuring that it is premised on trusting, respectful relationships, and encouraging collaboration and engagement between researchers and participants. Importantly, the TCPS 2 is published by the Government of Canada in a spirit of respect and is not intended to override or replace ethical guidance offered by Indigenous Peoples.

\section{Methods: Storytelling and Ceremony}

Unlike most academic papers, this piece was written as an iterative process, bringing together both written and oral contributions based on the co-authors' ideas and personal experiences. The Indigenous methodology of storytelling was used and was an essential component of the journey. Indigenous coauthors emphasize that storytelling is a way we share our histories and carry our truths. Storytelling is an Indigenous way of sharing knowledges and research and is one of many existing forms of knowledge (Christensen, 2012; Wright et al., 2012). Margaret Kovach (2009) articulated that "if research is about learning, so as to enhance the well-being of the earth's inhabitants, then story is research" (p. 102).

A story is about much more than the content. It has been used for political, social, and personal growth, and to document and then retell history. As described by Kovach (2009), "stories are vessels for passing along teachings, medicines, and practices that can assist members of the collective" (p. 95). They are not only about the knowledges, but also about the teller and the relationship the teller holds with that story. In this story, the co-authors write collectively, all together as storytellers. Entwined within the story are the relationships that were formed with this work and with each other. Knowledges and experiences conveyed orally by Indigenous co-authors were recognized as equal contributions and as an example of doing research "in a good way"; their words were transcribed verbatim and integrated into the paper. In 
this article, the resurgence of history and the story of this journey are shared, and in doing so the coauthors "accept the guardianship of bringing oral story into academia" (Kovach, 2009, p. 103) and bestow a responsibility on the readers to honour this story by forming a relationship with it and with the authors while reading (Wilson, 2008).

Incorporating Indigenous ceremony was critical to the process, as it must be when conducting research "in a good way." Following a recommendation by Doris to integrate Indigenous ceremony into this article, Opening and Closing Prayers were provided by Mohawk Elder Mike Standup. Also, the Teachings shared during the Indigenous Women's Data Transfer Ceremony by Elder Mike Standup were kindly shared with permission in this article.

Doris suggested that the story be told as an analogy of a journey of two boats to describe Mona and her allied research team in their vessel and Doris with Indigenous researchers and leaders in theirs; together they journeyed over varied terrain: wide lakes, rough waters, calm streams, and both easy and difficult portages. ${ }^{2}$ As partners, they move forward together in trust, always aiming to contribute to the healing journey and wellbeing of Indigenous women living with HIV in Canada, and to support Indigenous women in the reclamation of their power.

Through storytelling, the team's journey is told: from relationship building at the beginning of the journey, to working together in partnership with a common vision, and then to the Indigenous Women's Data Transfer Ceremony, which Doris referred to as a portage; then the journey continues with reflections from Indigenous and allied researchers. Finally, Doris felt it would be meaningful to enhance the storytelling aspect of this article by interweaving the "herstory" of an Indigenous woman living with HIV and AIDS (as a way to honour her own way of storytelling and reclaim and resurge herstory) throughout with a beginning, middle, and end.

My name is Claudette Cardinal. I come from Enoch and Kehewin Cree Nations of Alberta. This is my journey, as an Indigenous woman in the process of reconciling with myself. This is my journey as an Indigenous woman living with HIV and AIDS.

To reconcile means to coexist in harmony. I reconciled with my culture as an Indigenous woman and with HIV. Growing up I was judged and made fun of as an Indigenous child, and because of it, I learned how to be a runner.

When I was diagnosed with HIV, I ran. I feared judgment. I ran away from the life I had in Alberta and I went as far west as I possibly could go. I relocated to Victoria, British Columbia to seek health care because I did not want to be treated in my home province. I was told I had two years to live. Now it is my 23rd year of living positive. (Claudette Cardinal's story, Part 1)

\footnotetext{
${ }^{2}$ A portage is the practice of carrying a watercraft over land, either between two bodies of water or around an obstacle.
} 
Peltier et al.: A Journey of Doing Research "In a Good Way"

\section{Results: The History of our Journey}

\section{The Beginning of the Journey-Building Relationships}

In 2011, three non-Indigenous HIV researchers, Mona, Angela, and Alexandra, were awarded a Canadian Institutes of Health Research (CIHR) grant for a large national community-based research (CBR) project entitled: The Canadian HIV Women's Sexual and Reproductive Health Cohort Study (CHIWOS; Loutfy et al., 2017). This project aimed to characterize women-centred HIV care and its impact on the health outcomes of women living with HIV in Canada, initially focused on women in Quebec, Ontario, and British Columbia (BC). In the same year, Mona heard Doris, an Ojibwe woman from Wikwemikong on Manitoulin Island in Ontario, present Environments of Nurturing Safety (EONS) Aboriginal Women in Canada_Five Year Strategy on HIV and AIDS (2010-2015) written by CAAN's Voices of Women Standing Committee (CAAN, 2011). Mona was moved by: (a) EONS' values of freedom, respect, courage, and generosity; (b) the five strategic objectives with the mission to respond to HIV/AIDS women-specific issues where Indigenous women living with HIV are equal partners in decisions that impact their health and the health of their children and families; and (c) the 15 Positive Aboriginal Women Statements for the creation of safe spaces where Indigenous women living with HIV can begin or continue healing journeys. EONS called for equal representation of Indigenous women at every table and for the elimination of systemic barriers that hinder their meaningful engagement (CAAN, 2011). As Mona was excited to see the similarities between EONS and CHIWOS, she approached Doris and suggested that they partner and work together. With that, they each entered the water-Mona and her allied research team in their boat and Doris with Indigenous researchers and leaders in theirs.

\section{Entering Open Waters-Working Together in Partnership}

To strengthen the partnership between CHIWOS and EONS, Doris and her team of Indigenous women leaders met with Mona in 2011 and asserted that CHIWOS should have an Indigenous Advisory Board. The group held a retreat, which Doris named "N'Ginaajiiwimi: The essence of who we are is beautiful." This led to the formation of the Indigenous Advisory Board to CHIWOS, named the CHIWOS Aboriginal Advisory Board-Prioritizing the Health Needs of Positive Aboriginal Women (CAABPAW), and the roll-out of CHIWOS in two additional provinces: Saskatchewan and Manitoba. In Saskatchewan, Dr. Carrie Bourassa, a Métis researcher, joined CHIWOS as the Saskatchewan principal investigator, and the roll-out of CHIWOS is led by her Indigenous community-based health research lab, Morningstar Lodge. In Manitoba, allied researchers Drs. Marissa Becker and Sharon Bruce joined CHIWOS as the Manitoba principal investigators with the essential partnership of Ms. Laverne Gervais, an Anishnabe-Dakota-French Canadian woman from Treaty 1 territory in Winnipeg who works as the Program Coordinator at Ka Ni Kanichihk, which means "for those who lead."

Described further in detail elsewhere (Loutfy et al., 2016), CHIWOS is a national longitudinal quantitative study that used CBR principles to carry out three peer- and ally-administered surveys (Kaida et al., 2019) with women living with HIV in BC, Ontario, and Quebec at 18-month intervals. CHIWOS used purposive sampling to over enroll harder-to-reach populations of women living with HIV who experience heightened barriers in accessing care and participating in research (e.g., Indigenous women). Through the connections, trust building, and hard work of the CHIWOS Indigenous research 
assistants (V.L., C.C., K.B., J.C., C.T., C.M.), 318 Indigenous women living with HIV (161 from BC, 149 from Ontario, and 8 from Quebec) were enrolled and engaged in the baseline survey. The CHIWOS Indigenous research assistants obtained informed consent from all participants prior to them completing the survey. For Saskatchewan and Manitoba, rather than quantitative surveys, the teams of Indigenous and allied researchers decided that arts-based and Indigenized data collection methods were more appropriate in their contexts to answer the same CHIWOS research questions.

At the early CAAB-PAW meetings, there was a sense of the historical tension described earlier. On one hand, CHIWOS had an extensive amount of rich quantitative data provided by Indigenous women living with HIV; yet the same questions kept resurfacing: "What should we do with the data and how do we handle the data 'in a good way'?" It was then, after re-reading the TRC (2015a), Mona had the idea of a ceremony to return the CHIWOS data to the Indigenous communities, Indigenous participants, Indigenous research assistants, and Indigenous leaders. This was in line with Indigenous research ethical protocols, such as $\mathrm{OCAP}^{\circledR}$ and equivalent Métis and Inuit principles (Riddell et al., 2017), and could address the tension and struggle that CHIWOS was facing (i.e., the impasse, or portage as per the analogy of the boats). The role of the TRC is important in this journey because it partly acts as a navigational map for the two boats as Indigenous leaders and allied researchers are working together in trust. As outlined on the TRC's website, "the TRC hopes to guide and inspire Aboriginal peoples and Canadians in a process of reconciliation and renewed relationships that are based on mutual understanding and respect" (TRC, n.d., p. 1); we used its content, spirit, and Calls to Action as a guide for doing research "in a good way."

Also important was the consideration of the United Nations Declaration on the Rights of Indigenous Peoples (UNDRIP, 2007), which affirms the right of Indigenous Peoples to self-determination, to be treated as respected partners in matters affecting them, and to be able to control and protect their traditional knowledge. Additionally, it was acknowedged that the Indigenous women living with HIV who agreed to share their data trusted that it would be used "in a good way." CHIWOS researchers and partners hold the stories of hundreds of Indigenous women living with HIV, including a number who have since died; we feel that we have a responsibility to tell these women's stories and examine and use the data in a meaningful way that will lead to change and justice for Indigenous women living with HIV, their children, and their communities. 
I have been involved with CHIWOS since the very beginning. In 2011, I became a Community Advisory Board member to inform the CHIWOS survey and offer my lived experiences as an Indigenous woman living in $\mathrm{BC}$ and visitor in this territory. Once data collection began, I was hired as a peer research associate (PRA) in 2013 and have been one for over six years. As a PRA, I have witnessed the CHIWOS study process to be empowering for both the participant and the PRA. Transitioning from a participant to a PRA gives you clarity of who you were, who you are today, and your hopes for who you want to be down the road. During my experience as a PRA, the best times are when chatting with another woman during the survey and acknowledging that she does not have to be on guard, reassuring her that she can just breathe and not worry about others hearing the conversation and their judgment. Sometimes this was the women's first conversation of disclosing their status. I try to keep them positive, to reassure them they have done nothing wrong. These connections with the women being interviewed are profound; they share their stories that we intently listen to and we strive to honour them. (Claudette Cardinal's story, Part 2)

\section{The Portage-The Indigenous Women's Data Transfer Ceremony}

After six years together, in which time we created a questionnaire (Abelsohn et al., 2015), interviewed and analyzed data from 1,422 women living with HIV (see cohort profile for details in Loutfy et al., 2017), the journey reached what Doris called the "portage" — in other words, the Indigenous Women's Data Transfer Ceremony. This beautiful ceremony, which captured both the worldly and spiritual importance of this journey, took place on April 5, 2017, with the CHIWOS team's lead researchers, Indigenous researchers, and community leaders present.

The Ceremony was conducted on the unceded territory of the Kanien'kehá:ka people. Carrie Martin, a Mi'gmaq woman and team member, helped to organize the event using local protocol. She asked Elder Mike Standup if he would do the honour of delivering the Opening and Closing Prayers. She also asked him to share his Teachings on the Wampum Belt and any Teachings that came to him; it was the Teachings of the Water that he shared.

As is customary in First Nations communities, the Ceremony began with Mona making an offering of a tobacco tie to Elder Mike, which he accepted. In ceremony, it is important to follow proper cultural Indigenous protocol, such as providing the offering of tobacco. The offering of tobacco represents an agreement between the Elder and the person making the offering that, if accepted, the Elder will provide prayer and guidance and deliver on the request.

The event started with Elder Mike at the podium; beside him were the Indigenous organizers and team members. At the first table were CHIWOS principal investigators and allied researchers. The room was filled with approximately 50 researchers, research students, and coordinators who were in attendance as part of the CIHR Canadian HIV Trials Network's annual meeting.

Elder Mike noted that the Teachings of the Water and the Wampum Belt go hand in hand. He shared the following: 
A Huron man from Wendake is very knowledgeable about how to activate the Wampum Belt by immersing it in water. He would then be the medium through which the wampum would speak and share knowledge from the Spirit World when it was asked a question.

The Water Teachings:

Water is the most important element. It is used in teachings, ceremonies, and can even be used for Smudging when you cannot burn medicines [as in the case of most hospitals]. For this, it is suggested to make cedar water and use a spray bottle to Smudge. In this sense, it is noninterfering with technology.

A Japanese man named Dr. Emoto did numerous studies on healing methods. He determined that the power of suggestion, love, and gratitude being expressed to the water will impress love and gratitude into the water which is then transferred back into the physical body when we drink the water.

The molecular structure changes into a crystalline form after passing vibrations to the water. This can enhance and heal the body and also change the molecular structure of the body when we drink it.

Alternatively, we can conduct a water ceremony and offer the love and gratitude to the water and then pour that water into the river to heal the water.

Our people always had these teachings, but they were forgotten for a while and are beginning to return to our consciousness because of pollution and the harm done to our waters. We have the power to heal the waters through spirit and promote its return to health.

As he spoke, time stood still. The listeners could feel the power of his words and the Teaching could be felt in one's cells. Elder Mike went on to the Teaching of the Two Row Wampum Belt Treaty:

This was a treaty originally signed between the Mohawk people and the Dutch; they were the first ever European group with whom we made a treaty. To commemorate the Treaty, we made a belt with white and purple wampum beads (white background base with purple parallel lines).

The purple beads represent the parallel path we are both travelling together in tandem but never interfering with one another.

This treaty, although originally made between the Mohawk and Dutch people, can incorporate all Natives of North America and all Europeans. It really represents the relations between two Nations or even simply two people. The Treaty can be applied to any relationship.

The Wampum Belt is a reminder for the need to practice non-interference between two relations. Stepping out of your vessel into the vessel of someone else sets both vessels off balance and the relationship begins to disintegrate. The Wampum Belt serves as a reminder to "mind your own business" and helps to put things back into perspective. It teaches us to deal with 
Peltier et al.: A Journey of Doing Research "In a Good Way"

things by travelling down the same path and in the same direction without getting in each other's way.

Next during the Ceremony, as is protocol, as a means of honouring those who are part of a gathering, Renée, Doris, and Carrie B. gave gifts to the six present CHIWOS co-principal investigators on behalf of CAAN.

Mona then handed over two USB sticks with the physical raw quantitative baseline data of the 318 Indigenous women living with HIV who participated in CHIWOS; one given to CAAN represented by Renée and one to Carrie B., representing the Morningstar Lodge. In line with protecting participant confidentiality, the quantitative data were de-identified and stored on two encrypted passwordprotected USB sticks. At the institutional level, this transfer of data was approved by research ethics boards. Indigenous women living with HIV (Val, Claudette, and Doris) were also invited to be present on stage with Renée and Carrie B. Carrie B. and Renée spoke about how this was a historic event and one of the first times that Indigenous ethical principles were followed by academic researchers in such a way that the actual raw data was given back to Indigenous partners. The return of data to community members reflects a commitment to self-determination of Indigenous communities because ownership, control, access, and possession of data is fundamentally linked to self-determination. The Ceremony was aligned with the First Nations principles of $\mathrm{OCAP}^{\circledR}$ and equivalent Métis and Inuit principles and principles laid out in TCPS2's Chapter 9, whereby relationships were solidified in trust and reciprocity, Indigenous partners gained control, and cultural norms and ethical obligations of knowledge sharing were honoured (Moore et al., 2017). In some ways, this was extraordinary and meaningful because the data being returned were quantitative in nature, despite the historical tension in that quantitative data does not easily fit into Indigenous approaches to research or knowledge creation. Through the data transfer, Indigenous partners now physically possess and protect their collective information and have control in ensuring that the data are interpreted and used in strengths-based ways for the benefit of Indigenous communities. The event ended with a Closing Prayer by Elder Mike followed by singing and drumming of the "Strong Woman Song."

\section{Reflections from the Indigenous Community Members and Researchers}

As Indigenous members of the CHIWOS team-investigators, knowledge users, PRAs, and participants - we see this journey together is a commitment to do research "in a good way." We have been challenged to learn together, to seek direction from the communities we represent, to support Indigenous women through the data collection process, and to bring creativity to the research process. Contributing to the design and administration of a lengthy survey has required ongoing reflection on the impact the data will have in our communities. Holding the stories of Indigenous women and respectfully re-telling them with a collective voice requires careful attention to the great diversity of our peoples and our shared experiences. The potential of CHIWOS for positive change for Indigenous women living with HIV is our motivation and our hope.

In addition to the obvious emotional reflections expressed by our Indigenous team, we acknowledged that this Data Transfer Ceremony was among the first of its kind and a true reflection of Indigenous ethical principles. The significance of this ceremony and the transfer of the data should not be 
understated. In their extensive report, the Royal Commission on Aboriginal Peoples (RCAP, 1997) presented:

The gathering of information and its subsequent use are inherently political. In the past, Aboriginal people have not been consulted about what information should be collected, who should gather that information, who should maintain it, and who should have access to it. The information gathered may or may not have been relevant to the questions, priorities and concerns of Aboriginal peoples. Because data gathering has frequently been imposed by outside authorities, it has met with resistance in many quarters. (Steffler, 2016, p. 151)

For many years, Indigenous communities have not had access to their own data and, as a point of fact, have not been able to control or possess their data. It must be recognized that $\mathrm{OCAP}^{\circledR}$ is selfdetermination applied to research and is also, in fact, a First Nation political response to colonial approaches to research and information management (FNIGC, 2015). Thus, this Data Transfer Ceremony was much more than a symbolic event; rather, it was a tangible opportunity for Indigenous researchers to put self-determination in research into action. In light of the TRC Calls to Action relating specifically to health, the timing of the data transfer was vital. There are five specific Calls to Action (TRC, 2015a) relating to health and one that speaks directly to health research:

19. We call upon the federal government in consultation with Aboriginal peoples, to establish measurable goals to identify and close the gaps in health outcomes between Aboriginal and nonAboriginal communities, and to publish annual progress reports and assess long-term trends. Such efforts would focus on indicators such as: infant mortality, maternal health, suicide, mental health, addictions, life expectancy, birth rates, infant and child health issues, chronic diseases, illness and injury incidence, and the availability of appropriate health services. (p. 161)

As a truly emotional event, this ceremony was symbolic of something important to the restoration and reclamation of our cultural traditions as Indigenous community members and researchers. Prior to colonization, we as Indigenous Peoples lived autonomously in our territories and respectfully with nature. As researchers, we learned from all aspects of our environment to live well and sustain ourselves. We completed the circle together and brought ourselves back to where we used to be: to a place where we once again are proud keepers of our knowledge and our ceremonies.

In completing this circle, information was shared in both directions: In the spirit of reciprocity, we were, and remain, all teachers and students. By coming together as a team of Indigenous Peoples and nonIndigenous allies, we have been able to join hands and do research "in a good way" as equals. Together, we were able to realize the good that our ancestors want for us as they join us and help us when we call upon them in ceremony.

\section{Reflections from the Allied Researchers and Team Members}

As the allied researchers on this team, we are directed by our Indigenous partners, apply the TRC and its Calls to Action, and rely on important bodies of Indigenous literature (Estey et al., 2009; Kovach, 2005; Kovach, 2009; Rozario, 2007; Smith, 2013; Wilson, 2008) to guide us in doing research "in a good way." Through our work with CAAN, Ka Ni Kanichihk, Morningstar Lodge, and our Indigenous team members, we as CHIWOS researchers have committed to a path of reconciliation. Being on a path of 
Peltier et al.: A Journey of Doing Research "In a Good Way"

reconciliation is not meant to be a grand statement, but rather one of respect, humility, and constant self-reflection.

As non-Indigenous women in Canada, we acknowledge that we are privileged to live, play, and work on the ancestral and traditional territories of Indigenous Peoples. Wrapped within this acknowledgement must exist a reckoning with how we have benefitted from the legacy of colonization, including how our ways of knowing have been privileged over Indigenous ways of knowing, with varied and at times devastating consequences to Indigenous Peoples.

In our role as CHIWOS researchers, we commit to ethical principles and standards in order to protect the dignity, rights, and wellbeing of all research participants. For example, a key message presented throughout Chapter Nine of the TCPS2 is that community engagement and trust building are integral to conducting ethical research involving Indigenous Peoples and communities. As allied CHIWOS researchers, we are indebted to Indigenous women, who have trusted and taught us, and emphasized conducting research "in a good way" (Wingert \& White, 2017). Through this journey, we have come to view a commitment to high-quality research practices as much more than a scientific pre-requisite. It is an expression of deep respect for the CHIWOS participants and collaborators, a demonstration of responsibility for the stories shared, and a sign of accountability to the communities we are meant to serve.

We honour the Elders, Indigenous colleagues, and all our relations for the wisdom they share. It has been a distinct privilege of our professional and personal lives to be granted the gift of such stories, experiences, and relationships that have opened our minds, our hearts, and our souls.

\section{Reflection from an Allied CHIWOS Researcher}

My name is Sharon, and I am an allied researcher. I went to the Ceremony with mixed feelings for a couple of reasons. First, I felt as though I did not belong. Manitoba was fairly new to the project and we were not included in the data that were being transferred. Did we have a place in the Ceremony? Maybe we should be part of the audience? Second, I wondered why such a ceremony was required in the first place. Was there not a research agreement that explicitly defined data ownership? Were the communities and organizations not already co-owners of the data? My concern was that the Ceremony was an enactment of the colonial (power-laden) research relationship (i.e., researchers giving others the data). The imbalance in power seemed inherent in the transfer. But the CHIWOS team is the most generous group of people I have ever worked with. They are patient, open, and generous. They provide space for doubt and discussion. The Ceremony was moving and meaningful. Upon reflection, I see that the transfer was a coming together of team members in ceremony to decolonize research relationships and the colonial processes that go with it - for example, where data can be housed. The Data Transfer Ceremony was important because I saw that a written research agreement, something now promoted by funders as a requirement for ethical research, may also be a colonial construct. The transfer was research as ceremony and I am fortunate to have been present, to have been given space to reflect, an opportunity to decolonize my thinking and ways of doing, and to have learned valuable lessons. 


\section{The Journey Continues}

The storytelling continues as two graduate student team members who joined later on in the journey share their reflections. The continuation of the journey is an important part of this process as it shows commitment to expanding relations and continuing on the path of reconciliation.

\section{Reflection from an Indigenous PhD Student}

My name is Laura. I am a member of the North Bay/Mattawa Algonquin First Nation. I grew up in our ancestral territory in a small community in northern Ontario. My Indigenous roots come from my mother's side of the family and my father is of Western European descent. Due to the intergenerational effects of colonization, my mother did not grow up speaking Algonquin or participating in Indigenous culture, and by proxy neither did my siblings or I. Even though we were not taught our language or introduced to cultural activities growing up, we were taught to have a great respect for Mother Nature and everything she provides. In this sense, I feel very tied to my culture.

While I always knew my Indigenous roots and had a value system consistent with Indigenous culture, until adulthood I knew very little about Indigenous ceremonies and the broader Indigenous population. I was raised in the Western education system and saw the world through that lens. While completing my Masters in Statistics, I was given the opportunity to work on a project led by the Ontario HIV Treatment Network to gain a better understanding of HIV among Indigenous populations in Ontario. This was the beginning of my journey into Two-Eyed Seeing (Hall et al., 2015).

I have since started my $\mathrm{PhD}$ in aging among Indigenous populations at the University of Toronto and continue to work in Indigenous HIV research. While I am still relatively new to Indigenous ways of knowing, I feel as though I have grown and learned an enormous amount from being part of the Indigenous research community. Historically, as a quantitative epidemiologist and statistician, I made sense of the world through numbers, paying little attention to the words surrounding them. Being a part of this journey has opened my eyes to the story behind the numbers. Listening to the emotion, excitement, and enthusiasm of the women telling stories of the Data Transfer Ceremony brought meaning to the numbers. I have learned the vital importance of ceremony and process in Indigenous research and switched my thought pattern from a deficits-based model to a strengths-based approach. I am still new to this journey and have much to learn, but I could not be more grateful to be joined on this path by such an incredible group of strong and knowledgeable women.

\section{Reflection from an Allied PhD Student}

My name is Denise and my journey with CHIWOS first began when I was a medical resident and I have had the honour of walking alongside an inspiring team of Indigenous and allied researchers as I continue my training, now as a $\mathrm{PhD}$ student. I currently live in Northwestern $\mathrm{BC}$, on the territory of the Tsimshian Nation, where I provide clinical care in parallel with my research endeavours. As a nonIndigenous researcher, I have had to carefully think about my own relationship to Indigenous health research and, looking back, I can see how much this relationship has changed. I began with naïve optimism that my work would help improve the health of Indigenous populations. At that time, I knew a bit about Canada's colonial past, but I am only now starting to understand its presence. This learning has occurred through relationship building, conversations, readings, and courses taught by Indigenous 
Peltier et al.: A Journey of Doing Research "In a Good Way"

scholars. I now continue this path but have transformed naivety into thoughtful dedication and critical reflexivity. I constantly ask myself if it is my place to do research with these communities. I ask myself if it is okay to list "Indigenous health" as a keyword when I list my areas of interest and expertise. I do not see these inner dialogues as problematic. As a non-Indigenous researcher, it is the absence of these dialogues that would be problematic and colonial. It has taken me several years to realize that although I have been graciously welcomed by Indigenous colleagues in the field of HIV, I was never invited.

When I was first asked to join CAAB-PAW, it was for my experience working with the CHIWOS data and my role was to support data analysis based on research priorities of CAAB-PAW. I began with some preliminary analyses to provide $\mathrm{CAAB}-\mathrm{PAW}$ with an overview of the data. Approximately six months later, I was on a CAAB-PAW teleconference call explaining the ways I could help out with the analysis and I was politely informed that my help would not be needed because the group wanted an Indigenous analyst to do the work. For a moment, I felt hurt and devalued, but I realized that this was not about me. This was about Indigenous self-determination in research and real allyship was about supporting Indigenous scholars, not doing research about, for, or with Indigenous Peoples. Recognizing that there were several talented Indigenous researchers who would be able to support this analysis, I decided to resign from CAAB-PAW. I felt a sense of loss, cried, and then called Mona to let her know that I did not want to occupy the space that should be held by an Indigenous researcher and to thank her for giving me the opportunity to be a part of CAAB-PAW. We spoke for a long time and together came to the realization that I did still have a role on CAAB-PAW. As a trainee, I was learning how to be an allied researcher and I could contribute by learning to do research "in a good way." I contacted Doris and Carrie B., and they were supportive of my ongoing involvement. So now, I continue to feel honoured to be a part of this group, but I know that it is my responsibility, as an uninvited guest, to do research "in a good way." If I am able to do this, I may earn the title of "ally." If not, I should leave.

\section{The Journey's Next Steps}

As described in this article, we prioritized relationship building and the process of following Indigenous ways as critical first steps of doing research “in a good way." Through the Indigenous Women's Data Transfer Ceremony, the physical raw data of the Indigenous participants were given to the Indigenous researcher partners. Indigenous researchers and community members, through CAAB-PAW, will direct the next steps, which include formulating research questions, analyzing the data through an Indigenous lens and by an Indigenous statistical analyst, and communicating the stories of Indigenous participants from a strengths-based perspective. These are important components of doing research "in a good way" as outlined in Walter and Andersen's (2013) Indigenous Statistics: A Quantitative Research Methodology. As such, no conference abstract or peer-reviewed papers have been published to date with this data. Prior to such publications, the results and the accompanying stories developed will be presented at a symposium for Indigenous women living with HIV where hundreds of women will be in attendance. The team feels that it is important to present and review the findings and stories with the women that they are telling the stories about. This is an opportunity to ensure the stories resonate with their experiences and gives them control over the stories being told about them prior to publication. Throughout the next steps, we take guidance from the TRC (n.d.), which explains that reconciliation is an ongoing individual and collective process. We commit to this ongoing iterative process with respect and mindfulness, continuously evaluating our potential impact. 
I often think about the 73 women in CHIWOS that have passed; their stories are still with us. It is an outstanding challenge to honour the women's stories in the research process. Sometimes I wonder if to do this, maybe we need to choose different ways to capture the stories and translate them. Traditionally, we don't use surveys to collect our stories - we sit around, our community Elders are present, we have food, we laugh, we tell stories, we feast-this is how our stories were told. For now, we have chosen to honour the quantitative data of Indigenous women by gifting them to allied researchers who are on this journey with us-a journey that requires mutual respect from all parties and a deep understanding that women with HIV are more than capable to do more parts of research; it requires a belief that there is always a place for everyone. Most importantly we must remember that to do research "in a good way," a way that is adherent to Indigenous ways of knowing and thinking, it cannot be rushed. Communities must be first ready and if ready, involved in every step of the way. Everyone must be at the table. Researchers must learn to see from the participants' point of view-a role reversal.

I just found out that I am from Bear Clan. This is my journey-a learning process of who I am as an Indigenous Cree woman. This is our journey-of learning to do research together "in a good way." (Claudette Cardinal's story, Part 3)

\section{Discussion}

We, as Indigenous researchers and leaders and allied researchers, have written this unique process paper using storytelling, and in ceremony with Opening and Closing Prayers. We interwove the herstory of an Indigenous woman living with HIV and AIDS, and we analogized our partnership as a journey of two boats-a journey that is continuing. In addition to relationship building and working together to overcome challenges, which led to the Indigenous Women's Data Transfer Ceremony, the reflections captured are an important part of reconciliation, allyship, and doing research "in a good way."

Historically, non-Indigenous researchers have often carried out analyses themselves, producing conference abstracts and manuscripts, with data that are often out of context and not usable by communities (Drawson et al., 2017). We asked how we can decolonize the way that research data are collected, analyzed, interpreted, and disseminated. The participating Indigenous women wanted us to know about the hardship that they have endured, but they also wanted us to know about their resilience, magnificence, and beauty. As a response, working together in genuine partnership and following Indigenous protocols were important in building the trust needed to allow those stories to be told "in a good way" and to contribute to making a difference. Building and nurturing relationships and the partnership itself were critical in doing research "in a good way" as they allowed for meaningful dialogue, listening, and learning about the worldviews, protocols, and priorities of the communities in partnership.

Ceremony is also critical in decolonizing the research process and doing research "in a good way." Doris, Renée, and Carrie B. with the CHIWOS Indigenous PRAs indicated that the Indigenous Women's Data Transfer Ceremony was truly a ceremony and was a critical and unique step towards changing the way research is done so as to ensure it is done "in a good way." A significant aspect was that the Elder played a key role in the Ceremony, the preparations, and this article. As shared by Flicker et al. (2015), "Elders often provide the wisdom, knowledge, and ceremonial guidance to assist with research processes that respect the Indigenous worldviews" (p. 1149); thus, culturally appropriate protocols involving Elders 
should be followed. For example, tobacco ties are used to create relationships and secure a depth of knowledge from Elders; they act as a form of consent in the research process, and a way to reclaim the use of tobacco for its original sacred purpose, correcting misunderstandings of non-Indigenous peoples (Drawson et al., 2017). As argued by Wilson (2008) in Research is Ceremony, engaging Elders demonstrates respect for Indigenous ways of knowing and is necessary to bridge the divide and build stronger relations. Thus, doing research "in a good way" requires genuine respect for Indigenous ways of knowing and the engagement of Elders and Knowledge Keepers.

Further, research done "in a good way" is action-oriented, leading to programming and policies that are owned by and responsive to the needs of communities. In Research as Resistance, Kovach (2005) argued that Indigenous methodology is not merely a method, but a philosophical stance-one that is dedicated to the issues of social justice for Indigenous Peoples. The Indigenous Women's Data Transfer Ceremony signified a shift in power - the Indigenous researchers taking ownership of the physical data and now positioned to lead the analyses. This shift in power is enacted through ceremony, and other activities such as respecting collective knowledge and worldviews, the meaningful engagement and respect of community members, following of Indigenous protocols, ensuring research will benefit the community, the use of storytelling, engaging in research with meaning, and shifting the power of a research team to the Indigenous partners (Brown \& Strega, 2005). Therefore, collaborative research endeavours, such as those described in this article, will be meaningful and have an impact on programming when they prioritize the needs of the community with the underlying goals of research equity, community control, and social justice. Additionally, we reflected on the TRC Calls to Action within the health, business, and education sectors (TRC, 2015a), and we acknowledge that action is needed at all levels of research — the funders, research ethics boards, and individual researchers.

Indigenous ways teach that no one is perfect and there are diverse experiences that inform how to proceed; there are different views from different directions; lessons are important, and reflection is essential for all. For those of us who are privileged enough to work with research data, we must try to be humble, learn, and reflect upon and listen to the Teachings and the Elders. Reflecting on our positionality, relationships, and the meaning of allyship with a commitment to continually learn and improve are essentials to doing research "in a good way."

\section{Conclusion: Teachings and Learnings}

In conclusion, we are 19 women living on Turtle Island-First Nations, Métis, and allied-who have come together with an Elder on this journey and are honoured to work together and learn from each other. We learned that doing research "in a good way" requires the following: (a) building reciprocal relationships early in the research process and working together towards true partnership through the ongoing nurturing of those relationships; (b) following Indigenous protocols that emphasize selfdetermination and Indigenous ways of knowing; (c) coming together in ceremony to decolonize research relationships and colonial processes that go with them; (d) committing to action-oriented goals of research, such as a positive change for Indigenous women living with HIV through shifts in power and control; and (d) reflecting critically and continuously to contribute to reconciliation through research. Our work honours the Seven Sacred Teachings of Humility, Respect, Wisdom, Honesty, Love, Courage, and Truth. We gift you these teachings and learnings from our work so that together our research can be done "in a good way." 
In closing, I would like to say to everyone involved, from the helpers, to the clients, patients, families, friends, and supporters, to remember that when we are coming together to support our loved ones, our prayers, and our thoughts are the most important ingredient for our wellbeing.

To the people, the clients, you are always safe no matter where you go. The illnesses we have are not insurmountable and we can continue on with a good life despite our illnesses.

Remember to give thanks and gratitude to the forces that surround you. Prayer is an act of gratitude towards life and the universe. Remember to humble ourselves in helping us to change our state of mind.

In the spirit of healing, always walk the good path, always have gratitude, and always with a loving heart.

Nia:wen kowa

Closing Prayer, Elder Mike Standup

\section{References}

Abelsohn, K., Benoit, A. C., Conway, T., Cioppa, L., Smith, S., Kwaramba, G., Lewis, J., Nicholson, V., O’Brien, N., Carter, A., Shurgold, J., Kaida, A., de Pokomandy, A., Loutfy, M., \& CHIWOS Research Team. (2015). "Hear(ing) new voices": Peer reflections from community-based survey development with women living with HIV. Progress in Community Health Partnerships: Research, Education, and Action, 9(4), 561-569. https://doi.org/10.1353/cpr.2015.0079

The Aboriginal HIV/AIDS Community-Based Research Collaborative Centre (AHA Centre). (2018). AHA Centre: "Doing research in a good way"[Fact Sheet]. https://www.ahacentre.ca/ uploads/9/6/4/2/96422574/research_in_a_good_way_finaljune_2018.pdf

Ball, J., \& Janyst, P. (2008). Enacting research ethics in partnerships with Indigenous communities in Canada: "Do it in a good way." Journal of Empirical Research on Human Research Ethics, 3(2), 33-51. https://doi.org/10.1525/jer.2008.3.2.33

Brown, L., \& Strega, S. (Eds.). (2005). Research as resistance: Critical, Indigenous and anti-oppressive approaches. Canadian Scholars' Press.

Canadian Aboriginal AIDS Network (CAAN). (2011). Environments of nurturing safety (EONS) Aboriginal women in Canada-Five year strategy on HIV/AIDS (2010-2015). https://caan.ca/en/aphas-youth-women/women/eons-brochure/

Canadian Institutes of Health Research (CIHR), Natural Sciences and Engineering Research Council of Canada (NSERC), and Social Sciences and Humanities Research Council of Canada (SSHRC). (2018). Chapter 9: Research involving the First Nations, Inuit and Métis Peoples of Canada. Tri-Council policy statement: Ethical conduct for research involving humans (TCPS2). https://ethics.gc.ca/eng/tcps2-eptc2 2018 chapter9-chapitre9.html 
Peltier et al.: A Journey of Doing Research "In a Good Way"

Christensen, J. (2012). Telling stories: Exploring research storytelling as a meaningful approach to knowledge mobilization with Indigenous research collaborators and diverse audiences in community-based participatory research. The Canadian Geographer/Le Géographe canadien, 56(2), 231-242. https://doi.org/10.1111/j.1541-0064.2012.00417.x

Drawson, A. S., Toombs, E., \& Mushquash, C. J. (2017). Indigenous research methods: A systematic review. The International Indigenous Policy Journal, $8(2)$. https://doi.org/10.18584/ iipj.2017.8.2.5

Estey, E., Smylie, J., \& Macaulay, A. (2009). Aboriginal knowledge translation: Understanding and respecting the distinct needs of Aboriginal communities in research. Canadian Institutes of Health Research (CIHR). https://cihr-irsc.gc.ca/e/documents/aboriginal_knowledge translation_e.pdf

First Nations Information Governance Centre (FNIGC). (2015). The First Nations Principles of $O C A P^{\circledR} \cdot \underline{w w}$. FNIGC.ca/OCAP

Flicker, S., O’Campo, P., Monchalin, R., Thistle, J., Worthington, C., Masching, R., Guta, A., Pooyak, S., \& Thomas, C. (2015). Research done in "a good way": The importance of Indigenous Elder involvement in HIV community-based research. American Journal of Public Health, 105(6), 1149-1154. https://doi.org/10.2105/AJPH.2014.302522

Government of Canada. (n.d.). Canada's health care system. https://www.canada.ca/en/healthcanada/services/health-care-system/reports-publications/health-care-system/canada.html

Government of Canada. (2020, June 08). Origin of the name “Canada.” https://www.canada.ca/ en/canadian-heritage/services/origin-name-canada.html

Hall, L., Dell, C. A., Fornssler, B., Hopkins, C., Mushquash, C., \& Rowan, M. (2015). Research as cultural renewal: Applying Two-Eyed Seeing in a research project about cultural interventions in First Nations addictions treatment. The International Indigenous Policy Journal, 6(2). https://doi.org/10.18584/iipj.2015.6.2.4

Indian Health Policy 1979. http://caid.ca/IndHeaPol1979.pdf

Inuit Tapiriit Kanatami (ITK). (2018). National Inuit strategy on research. https://www.itk.ca/wpcontent/uploads/2018/04/ITK_NISR-Report_English_low_res.pdf

Kaida, A., Carter, A., Nicholson, V., Lemay, J., O’Brien, N., Greene, S., Tharao, W., Proulx-Boucher, K., Gormley, R., Benoit, A., Bernier, M., Thomas-Pavanel, J., Lewis, J., de Pokomandy, A., \& Loutfy, M. (2019). Hiring, training, and supporting peer research associates: Operationalizing community-based research principles within epidemiological studies by, with, and for women living with HIV. Harm Reduction Journal, 16(1). https://doi.org/10.1186/s12954-019-0309-3 
Kovach, M. (2005). Emerging from the margins: Indigenous methodologies. In L. Brown \& S. Strega (Eds.), Research as resistance: Critical, Indigenous, and anti-oppressive approaches (pp. 19-36). Canadian Scholars' Press.

Kovach, M. (2009). Indigenous methodologies: Characteristics, conversations, and contexts. University of Toronto Press.

Loutfy, M., de Pokomandy, A., Kennedy, V. L., Carter, A., O’Brien, N., Proulx-Boucher, K., Ding, E., Lewis, J., Nicholson, V., Beaver, K., Greene, S., Tharao, W., Benoit, A., Dubuc, D., ThomasPavanel, J., Sereda, P., Jabbari, S., Shurgold, J., Colley, G., ... Kaida, A. (2017). Cohort profile: The Canadian HIV women's sexual and reproductive health cohort study (CHIWOS). PLoS One, 12(9). https://doi.org/10.1371/journal.pone.0184708

Loutfy, M., Greene, S., Kennedy, V. L., Lewis, J., Thomas-Pavanel, J., Conway, T., de Pokomandy, A., O’Brien, N., Carter, A., Tharao, W., Nicholson, V., Beaver, K., Dubuc, D., Gahagan, J., ProulxBoucher, K., Hogg, R. S., \& Kaida, A. (2016). Establishing the Canadian HIV Women's Sexual and Reproductive Health Cohort Study (CHIWOS): Operationalizing community-based research in a large national quantitative study. BMC Medical Research Methodology, 16(1), 101. https://doi.org/10.1186/s12874-016-0190-7

Moore, C., Castleden, H. E., Tirone, S., \& Martin, D. (2017). Implementing the Tri-Council policy on ethical research involving Indigenous Peoples in Canada: So, how's that going in Mi'kma'ki? The International Indigenous Policy Journal, $8(2)$. https://doi.org/10.18584/iipj.2017.8.2.4

National Aboriginal Health Organization (NAHO). (n.d.). Principles of ethical Métis research. https://achh.ca/wp-content/uploads/2018/07/Guide_Ethics_NAHOMetisCentre.pdf

Rainie, S. C., Schultz, J. L., Briggs, E., Riggs, P., \& Palmanteer-Holder, N. L. (2017). Data as a strategic resource: Self-determination, governance, and the data challenge for Indigenous nations in the United States. The International Indigenous Policy Journal, $8(2)$. https://doi.org/10.18584/ iipj.2017.8.2.1

Riddell, J. K., Salamanca, A., Pepler, D. J., Cardinal, S., \& McIvor, O. (2017). Laying the groundwork: A practical guide for ethical research with Indigenous communities. The International Indigenous Policy Journal, $8(2)$. https://doi.org/10.18584/iipj.2017.8.2.6

Royal Commission on Aboriginal Peoples (RCAP). (1997). Report of the Royal Commission on Aboriginal Peoples: Volume 3. Gathering strength. http://data2.archives.ca/e/e448/ e011188230-03.pdf

Rozario, P. A. (2007). Research as resistance: Critical, Indigenous, and anti-oppressive approaches. Qualitative Social Work, 6(1), 121-125. https://doi.org/10.1177/ $\underline{1473325007074170}$

Smith, L. T. (2013). Decolonizing methodologies: Research and Indigenous Peoples. Zed Books Ltd. 
Steffler, J. (2016). The Indigenous data landscape in Canada: An overview. Aboriginal Policy Studies, 5(2). https://doi.org/10.5663/aps.v5i2.26992

Truth and Reconciliation Commission of Canada (TRC). (2015a). Honouring the truth, reconciling for the future: Summary of the Final Report of the Truth and Reconciliation Commission of Canada. Truth and Reconciliation Commission of Canada.

Truth and Reconciliation Commission of Canada (TRC). (n.d.). Truth and Reconciliation Commission of Canada FAQ's. http://www.trc.ca/about-us/faqs.html

Truth and Reconciliation Commission of Canada (TRC). (2015b). The Final Report of the Truth and Reconciliation Commission of Canada: Volume 1. Canada's Residential Schools: The history, Part 1. Origins to 1939. McGill-Queen's University Press. http://www.trc.ca/assets/ pdf/Volume 1 History_Part_1_English_Web.pdf

United Nations Declaration on the Rights of Indigenous Peoples, September 13, 2007. https://www.un.org/development/desa/indigenouspeoples/declaration-on-the-rights-ofindigenous-peoples.html

Walter, M., \& Andersen, C. (2013). Indigenous statistics: A quantitative research methodology. Left Coast Press.

Wilson, S. (2008). Research is ceremony: Indigenous research methods. Fernwood Press.

Wright, S., Lloyd, K., Suchet-Pearson, S., Burarrwanga, L., Tofa, M., \& Country, B. (2012). Telling stories in, through and with Country: Engaging with Indigenous and more-than-human methodologies at Bawaka, NE Australia. Journal of Cultural Geography, 29(1), 39-60. https://doi.org/10.1080/08873631.2012.646890

Wingert, S., \& White, J. P. (2017). Introduction to the special issue: Reconciling research: Perspectives on research involving Indigenous Peoples. The International Indigenous Policy Journal, $8(2)$. https://doi.org/10.18584/iipj.2017.8.2.10 